\title{
The prevalence of EGFR mutation in patients with non-small cell lung cancer: a systematic review and meta-analysis
}

\author{
Yue-Lun Zhang ${ }^{1,2}$, Jin-Qiu Yuan ${ }^{1,2}$, Kai-Feng Wang ${ }^{3}$, Xiao-Hong Fu',2, Xiao-Ran \\ Han $^{1,2}$, Diane Threapleton ${ }^{1}$, Zu-Yao Yang ${ }^{1,2}$, Chen Mao ${ }^{1,2}$, Jin-Ling Tang ${ }^{1,2}$ \\ ${ }^{1}$ Division of Epidemiology, The Jockey Club School of Public Health and Primary Care, The Chinese University of Hong Kong, \\ Hong Kong, China \\ ${ }^{2}$ Shenzhen Municipal Key Laboratory for Health Risk Analysis, Shenzhen Research Institute of The Chinese University of \\ Hong Kong, Shenzhen, Guangdong Province, China \\ ${ }^{3}$ Division of Epidemiology, School of Public Health and Tropical Medicine, Southern Medical University, Guangzhou, Guangdong \\ Province, China \\ Correspondence to: Chen Mao, email: maochen@cuhk.edu.hk \\ Jin-Ling Tang, email: jltang@cuhk.edu.hk \\ Keywords: non-small cell lung cancer, epidermal growth factor receptor, prevalence, systematic review, meta-analysis \\ Received: May 17, $2016 \quad$ Accepted: September 25, $2016 \quad$ Published: October 12, 2016
}

\section{ABSTRACT}

Objectives: Estimate the epidermal growth factor receptor (EGFR) mutation prevalence in all non-small cell lung cancer (NSCLC) patients and patient subgroups.

Results: A total of 456 studies were included, reporting 30,466 patients with EGFR mutation among 115,815 NSCLC patients. The overall pooled prevalence for EGFR mutations was $32.3 \%$ (95\% CI $30.9 \%$ to $33.7 \%$ ), ranging from $38.4 \%$ (95\% CI: $36.5 \%$ to $40.3 \%$ ) in China to $14.1 \%$ (95\% CI: $12.7 \%$ to $15.5 \%$ ) in Europe. The pooled prevalence of EGFR mutation was higher in females (females vs. males: $\mathbf{4 3 . 7 \%}$ vs. $24.0 \%$; OR: 2.7, 95\% CI: 2.5 to 2.9), non-smokers (non-smokers vs. past or current smokers: $49.3 \%$ vs. $21.5 \%$; OR: $3.7,95 \%$ CI: 3.4 to 4.0 ), and patients with adenocarcinoma (adenocarcinoma vs. non-adenocarcinoma: $38.0 \%$ vs. $11.7 \%$; OR: 4.1, $95 \%$ CI: 3.6 to 4.8 ).

Materials and Methods: PubMed, EMBASE, and the Cochrane Library were searched to June 2013. Eligible studies reported EGFR mutation prevalence and the association with at least one of the following factors: gender, smoking status and histology. Random-effects models were used to pool EGFR mutation prevalence data.

Conclusion: This study provides the exact prevalence of EGFR mutations in different countries and NSCLC patient subgroups.

\section{INTRODUCTION}

Lung cancer is the most common cause of cancer death, claiming 1.59 million lives in 2012 worldwide [1]. Non-small cell lung cancer (NSCLC) accounts for approximately $85 \%$ of all lung cancers and chemotherapy is one of the key components in the treatment protocol [2]. Although there is strong evidence to show that standard chemotherapy in addition to best supportive care can prolong overall survival and improve the quality of life [3], prognosis remains poor, especially in patients with advanced NSCLC. The median overall survival and the 5-year survival rate is only 1 year and $3.5 \%$, respectively [4].

A large proportion of NSCLC patients have sensitizing mutations in exon 19 or 21 (approximately
45 and $40 \%$ of patients, respectively) which activate the tyrosine kinase domain in epidermal growth factor receptors (EGFR). The discovery of EGFR tyrosine kinase inhibitors (TKI) was regarded as a landmark finding in the treatment of lung cancer [5-8]. Targeted EGFR-TKI first-line treatment of sensitizing EGFR mutations results in longer PFS, improved health-related quality of life and decreased treatment-related severe side effects when compared with those who received standard chemotherapy $[6,7,9-13]$. Many clinical guidelines therefore recommend that all patients with sensitizing $E G F R$ mutations receive first-line treatment with these drugs [14-19], in addition to all patients with advanced or metastatic NSCLC $[2,20]$.

Despite benefits in using EGFR-TKIs for first-line therapy in all sensitizing mutations, in resource limited 
situations, targeted screening may be appropriate [21]. Knowledge on the prevalence of EGFR mutations in different patient subgroups could therefore inform policy and testing strategies. Existing individual studies may not be informative for estimating prevalence because of small sample sizes in case-series or non-representative sample selection. The mutation prevalence reported in whole study or sub-group populations also varies dramatically in published studies [22-30] and the reported prevalence rates are therefore currently inappropriate for applying to other populations. In order to obtain a more precise estimate of EGFR mutation prevalence in NSCLC patients and patient subgroups, we conducted this systematic review and meta-analysis.

\section{RESULTS}

We identified 6,221 potentially eligible citations, of which 456 studies were finally included (Figure 1). The majority of included studies were case series (56.6\%) and cohort studies (33.2\%). Sixty-six percent of the studies were conducted in Asian countries. The median sample size was 103, ranging from 11 to 18,246 . Median participant age was 63 years, $56.1 \%$ were males and $57.0 \%$ were past or current smokers. Histology was reported in $45.0 \%$ of studies and $73.3 \%$ of patients had adenocarcinoma. EGFR exon 19 or 21 mutation was assessed in $89.3 \%$ of the studies (see Table A.1 for study characteristics).

In total, 30,466 patients with an EGFR mutation were reported among 115,815 patients with NSCLC. The overall pooled prevalence of all EGFR mutations and $E G F R$ exon 19 or 21 mutations was $32.3 \%(95 \% \mathrm{CI}$ : $30.9 \%$ to $33.7 \%$ ) and $32.2 \%$ (95\% CI: $29.6 \%$ to $34.8 \%$ ), respectively (Table 1). EGFR mutation prevalence varied by study location and ethnicity: Asia had the highest prevalence $(38.4 \%, 95 \%$ CI: $36.5 \%$ to $40.3 \%)$ [China: $38.4 \%$ (95\% CI: $35.7 \%$ to $41.1 \%$ ); Japan: $36.6 \%$ (95\% CI: $33.2 \%$ to $40.0 \%$ ); Korea $32.4 \%$ (95\% CI: $28.0 \%$ to $36.8 \%)$, followed by North and South America $(24.4 \%$, 95\% CI: $22.1 \%$ to $26.8 \%)$ and Europe $(14.1 \%, 95 \%$ CI: $12.7 \%$ to $15.5 \%)$. The prevalence among different ethnicities were similar to study locations, with the prevalence of $38.8 \%$ ( $95 \%$ CI: $36.8 \%$ to $40.8 \%$ ) in Asian populations, $17.4 \%$ (95\% CI: $15.8 \%$ to $18.9 \%$ ) in Caucasians, $17.2 \%$ (95\% CI: $5.7 \%$ to $28.8 \%$ ) in AfricanAmericans, and $27.0 \%$ (95\% CI: $22.6 \%$ to $31.4 \%$ ) in mixed populations.

Many study or patient characteristics had little influence on EGFR mutation prevalence rates, including the disease stage at diagnosis, history of chemotherapy, mutation detection methods (post-hoc analysis of methods reported in 10+ studies) or year of study publication (posthoc analysis) (Table A.2 for post-hoc analysis).

Table 2 provides associations between of EGFR mutation prevalence and gender, smoking status, and tumor histology in Caucasian and Asian populations. Overall, prevalence was higher in females (females vs. males: $43.7 \%$ vs. $24.0 \%$; OR: $2.7,95 \%$ CI: 2.5 to 2.9 ) and the ORs did not differ significantly by ethnicity: Caucasian females vs. males OR 2.7, 95\% CI 2.3 to 3.3; Asian females vs. males OR 2.8, 95\% CI 2.6 to 3.1. The prevalence was also higher overall in non-smokers (nonsmoker vs. past or current smoker: $49.3 \%$ vs. $21.5 \%$; OR: $3.7,95 \%$ CI: 3.4 to 4.0 ). Among non-smokers, as compared to past or current smokers, the mutation prevalence in Caucasians was greater than in Asians: Caucasian nonsmokers vs. past or current smokers $39.8 \%$ vs. $10.8 \%$; OR: $5.2,95 \%$ CI: 4.4 to 6.3 ; Asian non-smokers vs. past or current smokers $52.2 \%$ vs. $26.3 \%$; OR: $3.3,95 \%$ CI: 2.9 to 3.6. NSCLC patients with adenocarcinoma were also far more likely to carry the EGFR mutation (adenocarcinoma vs. non-adenocarcinoma: $38.0 \%$ vs. $11.7 \%$; OR: $4.1,95 \%$ CI: 3.6 to 4.8 ) in overall participants. This observation was more striking in the Asian population (adenocarcinoma vs. non-adenocarcinoma: $44.7 \%$ vs. $12.5 \%$; OR: $5.3,95 \%$ CI: 4.4 to 6.4 ) than the Caucasian population (adenocarcinoma vs. non-adenocarcinoma: $19.7 \%$ vs. $9.6 \%$; OR: $2.2,95 \%$ CI: 1.7 to 2.7). The prevalence of $E G F R$ mutation was not different in patients diagnosed at different NSCLC stages and by chemotherapy use history.

The prevalence trends in different patient groups remained when countries with at least of 50 studies were assessed separately (China, Japan, Korea and U.S) (Table A.3 to A.6). Notable exceptions included a very low prevalence $(3.3 \%, 95 \%$ CI: $2.4 \%$ to $4.1 \%)$ among patients with non-adenocarcinoma patients in Japan (Table A.4) and the higher prevalence for those who previously received chemotherapy in Japan (45.3\%, 95\% CI: 37.7\% to $52.8 \%$ ) and Korea (34.8\%, 95\% CI: $18.4 \%$ to $51.2 \%)$ (Tables A.4 and A.5).

\section{DISCUSSION}

In this study, we found that approximately onethird of NSCLC patients harbor an EGFR mutation. Patients who are Asian, female, non-smokers, and have adenocarcinoma are more likely to harbor an EGFR mutation, which is consistent with previous studies [23, 29, 31-33].

Some previous systematic reviews were published reporting the prevalence of EGFR mutation in patients with non-small cell lung cancer [34-38]. These previously published work focused on patient subgroups such as smokers, adenocarcinomas or studies only in Chinese population. Moreover, all these previous reviews did not employ meta-analysis method to pool the prevalence from original studies. Despite of these difference, the pooled prevalence estimates we generated were similar to these smaller systematic reviews. The overall pooled prevalence in our study is similar to some existing large individual studies, though there is considerable variation among 
countries and individual studies may not be relied upon for accurate prevalence rates [39-41]. Individual study divergence from the pooled estimates likely reflects the patient characteristics within studies. EGFR mutation prevalence is clearly influenced by these characteristics and thus, this large review of whole populations and subgroups provides the best evidence for EGFR mutation prevalence $[42,43]$.
Recent clinical guidelines from the American Society of Clinical Oncology (ASCO) and the National Comprehensive Cancer Network (NCCN) recommend all patients with advanced or metastatic non-squamous NSCLC to receive EGFR mutation testing [2, 44]. A costeffectiveness analysis also supports mutation testing vs. no testing for eligibility of second-line gefitinib treatment, after the failure of platinum-containing doublet [45]. However,

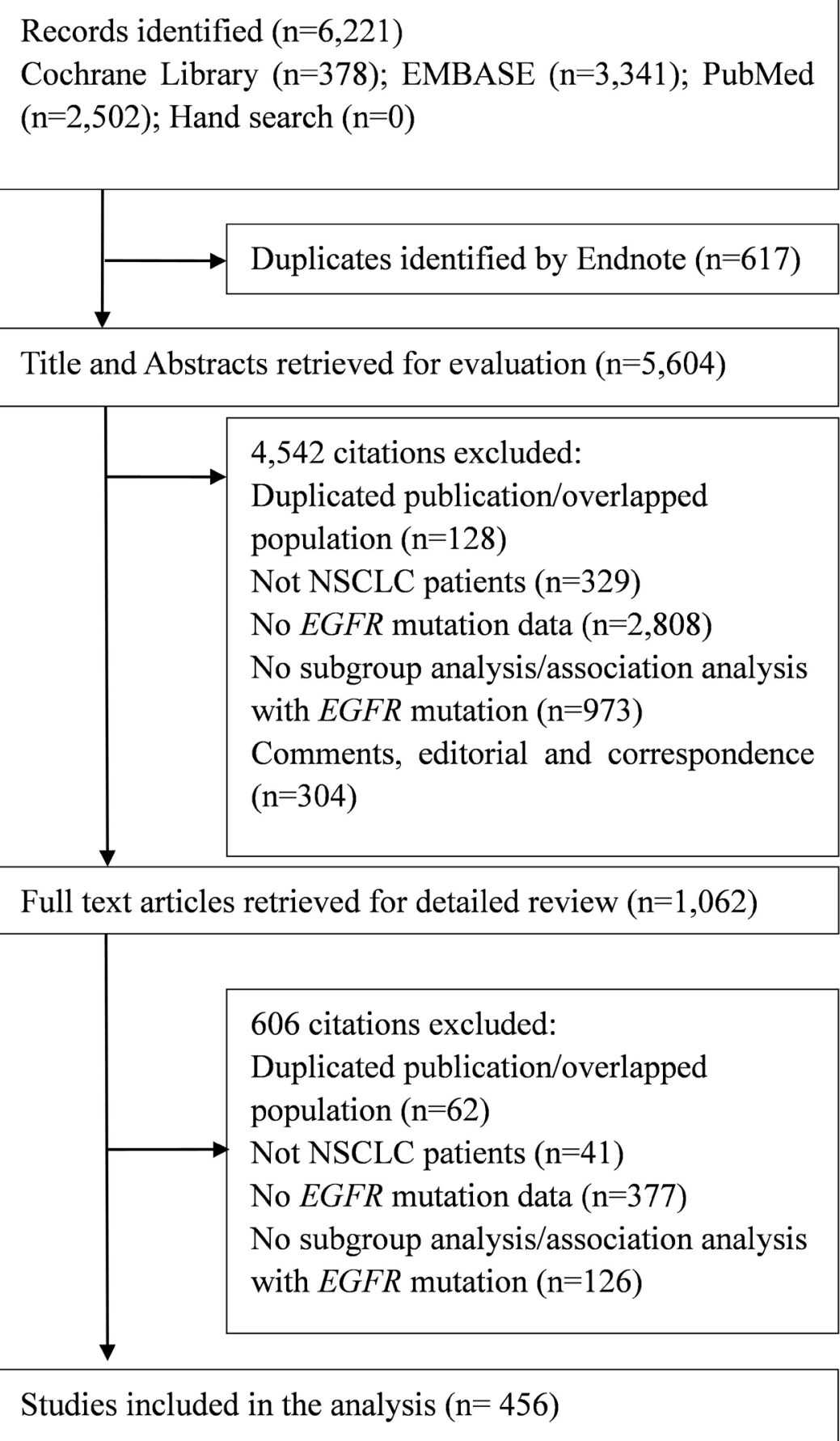

Figure 1: The flow chart of study selection. This figure provides detailed information for the study inclusion and exclusion. 
Table 1: The pooled prevalence of EGFR mutation in different NSCLC patient subgroups

\begin{tabular}{|c|c|c|c|c|}
\hline \multirow{2}{*}{ Group variables } & \multirow{2}{*}{ No. of studies } & \multirow{2}{*}{$\begin{array}{c}\text { Mutation prevalence, } \\
\%(95 \% \mathrm{CI})\end{array}$} & \multicolumn{2}{|c|}{ Tests of heterogeneity } \\
\hline & & & $\mathbf{P}$ & $I^{2}(\%)$ \\
\hline All studies & 456 & $32.3(30.9$ to 33.7$)$ & $<0.001$ & 97.3 \\
\hline \multicolumn{5}{|l|}{ Exon mutation location } \\
\hline Exon 19 & 343 & $16.7(15.8$ to 17.5$)$ & $<0.001$ & 93.2 \\
\hline Exon 21 & 330 & $12.3(11.6$ to 13.0$)$ & $<0.001$ & 92.7 \\
\hline Exon 19 or 21 & 95 & $32.2(29.6$ to 34.8$)$ & $<0.001$ & 95.5 \\
\hline Exon 18 & 90 & $1.2(1.0$ to 1.4$)$ & $<0.001$ & 48.6 \\
\hline Exon 20 & 93 & $1.7(1.4$ to 2.0$)$ & $<0.001$ & 64.2 \\
\hline \multicolumn{5}{|l|}{ Study location (continent)* } \\
\hline Asia & 304 & $38.4(36.5$ to 40.3$)$ & $<0.001$ & 95.6 \\
\hline America (North and South) & 81 & $24.4(22.1$ to 26.8$)$ & $<0.001$ & 96.8 \\
\hline Europe & 62 & $14.1(12.7$ to 15.5$)$ & $<0.001$ & 87.3 \\
\hline \multicolumn{5}{|l|}{ Study location (country) } \\
\hline Japan & 107 & $36.6(33.2$ to 40.0$)$ & $<0.001$ & 96.4 \\
\hline China & 104 & $38.4(35.7$ to 41.1$)$ & $<0.001$ & 93.0 \\
\hline Korea & 48 & $32.4(28.0$ to 36.8$)$ & $<0.001$ & 94.8 \\
\hline U.S. & 68 & $23.9(21.3$ to 26.5$)$ & $<0.001$ & 96.6 \\
\hline \multicolumn{5}{|l|}{ Ethnicity } \\
\hline Caucasian & 96 & $17.4(15.8$ to 18.9$)$ & $<0.001$ & 92.0 \\
\hline Asian & 301 & $38.8(36.8$ to 40.8$)$ & $<0.001$ & 95.8 \\
\hline African-American & 5 & $17.2(5.7$ to 28.8$)$ & $<0.001$ & 89.0 \\
\hline Mixed & 32 & $27.0(22.6$ to 31.4$)$ & $<0.001$ & 96.9 \\
\hline Unclear & 22 & $19.3(16.4$ to 22.2$)$ & $<0.001$ & 94.3 \\
\hline \multicolumn{5}{|l|}{ Gender } \\
\hline Male & 322 & $24.0(22.5$ to 25.4$)$ & $<0.001$ & 94.2 \\
\hline Female & 331 & $43.7(41.5$ to 45.9$)$ & $<0.001$ & 94.8 \\
\hline \multicolumn{5}{|l|}{ Smoking status } \\
\hline Non-smoker & 284 & $49.3(47.2$ to 51.4$)$ & $<0.001$ & 91.5 \\
\hline Past or current smoker & 280 & $21.5(20.2$ to 22.7$)$ & $<0.001$ & 92.2 \\
\hline \multicolumn{5}{|l|}{ Histology } \\
\hline Adenocarcinoma & 307 & $38.0(36.0$ to 40.1$)$ & $<0.001$ & 96.6 \\
\hline Non-adenocarcinoma & 203 & $11.7(10.6$ to 12.7$)$ & $<0.001$ & 83.6 \\
\hline \multicolumn{5}{|l|}{ Stage } \\
\hline Stage I & 73 & $34.0(28.9$ to 39.1$)$ & $<0.001$ & 97.4 \\
\hline Stage II & 55 & $29.9(25.0$ to 34.7$)$ & $<0.001$ & 84.9 \\
\hline Stage III & 85 & $33.8(29.8$ to 37.8$)$ & $<0.001$ & 89.0 \\
\hline Stage IV & 68 & $37.5(33.2$ to 41.7$)$ & $<0.001$ & 93.3 \\
\hline \multicolumn{5}{|l|}{ Chemotherapy } \\
\hline Chemotherapy & 42 & $33.8(27.1$ to 40.5$)$ & $<0.001$ & 97.8 \\
\hline No chemotherapy & 74 & $33.2(29.3$ to 37.1$)$ & $<0.001$ & 96.7 \\
\hline
\end{tabular}

Legend: This table provides pooled prevalence and results from heterogeneity test of EGFR mutation in all eligible studies and different subgroups

*Europe includes countries of the European Union and Norway, Switzerland, and Turkey; America includes Canada, the United States, Argentina, Brazil, Colombia, Mexico, and Peru; Asia includes China, East Asia, India, Japan, Korea, Malaysia, Singapore, Taiwan, and Thailand. 
Table 2: The association of EGFR mutation with gender, smoking status, and tumor histology in Caucasian and Asian populations

\begin{tabular}{|c|c|c|c|c|c|}
\hline \multirow{2}{*}{ Group variables } & \multirow{2}{*}{$\begin{array}{l}\text { No. of } \\
\text { studies }\end{array}$} & \multirow{2}{*}{ 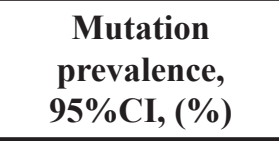 } & \multicolumn{2}{|c|}{ Tests of heterogeneity } & \multirow{2}{*}{ OR $(95 \% \mathrm{CI})$} \\
\hline & & & $\mathbf{P}$ & $I^{2}(\%)$ & \\
\hline \multicolumn{6}{|l|}{ Caucasian population } \\
\hline \multicolumn{6}{|l|}{ Gender } \\
\hline Female & 66 & $25.0(22.4$ to 27.7$)$ & $<0.001$ & 87.2 & $2.7(2.3$ to 3.3$)$ \\
\hline Male & 62 & $10.1(8.6$ to 11.5$)$ & $<0.001$ & 86.1 & 1.0 \\
\hline \multicolumn{6}{|l|}{ Smoking status } \\
\hline Non-smoker & 56 & $39.8(36.3$ to 43.2$)$ & $<0.001$ & 76.8 & $5.2(4.4$ to 6.3$)$ \\
\hline Past or current smoker & 56 & $10.8(9.4$ to 12.2$)$ & $<0.001$ & 82.9 & 1.0 \\
\hline \multicolumn{6}{|l|}{ Histology } \\
\hline Adenocarcinoma & 61 & $19.7(17.5$ to 21.8$)$ & $<0.001$ & 89.6 & $2.2(1.7$ to 2.7$)$ \\
\hline Non-adenocarcinoma & 40 & $9.6(7.6$ to 11.5$)$ & $<0.001$ & 84.1 & 1.0 \\
\hline \multicolumn{6}{|l|}{ Asian Population } \\
\hline \multicolumn{6}{|l|}{ Gender } \\
\hline Female & 231 & $51.1(48.9$ to 53.3$)$ & $<0.001$ & 88.0 & $2.8(2.6$ to 3.1$)$ \\
\hline Male & 228 & $28.7(26.7$ to 30.6$)$ & $<0.001$ & 92.6 & 1.0 \\
\hline \multicolumn{6}{|l|}{ Smoking status } \\
\hline Non-smoker & 197 & $52.2(49.7$ to 54.7$)$ & $<0.001$ & 91.5 & $3.3(2.9$ to 3.6$)$ \\
\hline Past or current smoker & 194 & $26.3(24.3$ to 28.2$)$ & $<0.001$ & 91.7 & 1.0 \\
\hline \multicolumn{6}{|l|}{ Histology } \\
\hline Adenocarcinoma & 214 & $44.7(42.4$ to 47.0$)$ & $<0.001$ & 93.8 & $5.3(4.4$ to 6.4$)$ \\
\hline Non-adenocarcinoma & 144 & $12.5(11.1$ to 13.9$)$ & $<0.001$ & 84.0 & 1.0 \\
\hline
\end{tabular}

Legend: This table provides pooled prevalence and results from heterogeneity test of EGFR mutation, and the pooled within-study ORs for the association between subgroup variables and EGFR mutation, in Caucasian populations and Asian populations respectively.

this may require substantial resources and effort and at present, the cost of EGFR mutation testing in some countries is met by patients' out-of-pocket expenses or from research funds, and can vary from U.S.\$ 150 to several hundred U.S.\$ [46]. Although non-invasive genetic testing methods exist [47], mutation detection using tumor tissues is still the gold standard for EGFR mutation testing. Such barriers prevent the widespread use of EGFR mutation testing and testing rates likely reflect the level of health service development and insurance coverage. EGFR mutation testing rates in NSCLC vary considerably among countries with approximately $9.6 \%$ in Chinese metropolitan areas in 2010 [48] and approximately $39.5 \%$ and $53.9 \%$ of patients in Korea and Japan, respectively [49, 50]. Where full coverage of screening is not available or possible, providers may target the patient groups identified in this review who are more likely to harbor mutations (e.g. 51.5\% of Asian females, $52.2 \%$ of Asian smokers, $44.7 \%$ of Asian patients with adenocarcinoma, and 39.8\% of Caucasian non-smokers harbor an EGFR mutation). Although EGFR mutation prevalence in some populations is relatively low at about $10 \%$ (e.g. $10.1 \%$ in Caucasian males and $12.5 \%$ in Asian patients with non-adenocarcinoma) screening must still be provided and only be targeted in resource limited settings. Given the fact that the efficacy of standard chemotherapy for patients with NSCLC remains limited, universal testing for $E G F R$ mutation may improve overall prognosis through the early use of first-line EGFR-TKI treatment.

A major strength of this work is the large number and range of studies included to estimate the prevalence of EGFR mutation in different NSCLC patient groups. These estimates can serve as the reference for the future research or policy making. However, several limitations of our study need to be mentioned. Firstly, since patients with higher likelihood of harboring an EGFR mutation are more likely to be tested, the overall prevalence 
may be overestimated. However, detailed recruitment information was not provided in many studies so we could not assess the influence of selection bias. Secondly, lack of relevant studies prevented us from further exploring the prevalence of EGFR mutation in some patient subgroups, such as Asian female non-smokers and Asian female adenocarcinoma patients. Thirdly, significant heterogeneity was found among included studies in almost all the analyses, which seems common in metaanalysis of single arm studies. The substantial difference in patient characteristics, clinical settings, and research methodologies among eligible studies may contribute to the high level of heterogeneity. Unfortunately, without individual patient data it is not possible to further subdivide prevalence estimates for precise patient groups such as women in the U.S. who are non-smokers and have adenocarcinoma. Despite noted limitations, we believe that this comprehensive synthesis of existing available studies provides valuable estimates of EGFR mutation prevalence.

This systematic review and meta-analysis estimates the prevalence of EGFR mutations in NSCLC patient subgroups. EGFR mutation prevalence estimates in these subgroups can inform policy makers of those patients who are more likely to benefit from EGFR-TKI treatment.

\section{MATERIALS AND METHODS}

\section{Data sources and search strategy}

We performed a comprehensive literature search in PubMed, EMBASE, and Cochrane Library from their respective inception to June 2013, with different combinations of the following keywords: "EGFR", "lung cancer", and "mutation". The literature search was restricted to human studies. No language restriction was applied. We manually checked reference lists of the included studies and relevant reviews to identify additional studies. Details of the search strategy are summarized in Table A.7.

\section{Study selection}

Studies reporting the prevalence of $E G F R$ mutation and odds ratio (OR) to estimate the association of $E G F R$ mutation with at least one of the following factors (gender, smoking status, and histology) in patients with NSCLC were considered eligible. For duplicate publications, we selected the most recent and complete version of publications. Two reviewers (WKF and YJQ) independently assessed the study eligibility. Any discrepancies were resolved by consensus or by consulting with a third reviewer (MC).

\section{Data extraction}

Data extraction was performed independently by two reviewers (WKF and YJQ). Disagreements were resolved by discussion between the two. If no agreement was reached, then a third researcher (MC) was invited to resolve the disagreement. The following data were collected from each study using a predefined data extraction form: study characteristics (such as the first author's name, year of publication, study location, study design, and sample size), patient characteristics (such as proportion of females, proportion of non-smokers, and proportion of adenocarcinoma), and the prevalence of $E G F R$ mutation (such as the number of patients with $E G F R$ mutation and $\mathrm{OR}$ for association of EGFR mutation with gender, smoking status, and histology).

\section{Outcome measure and subgroup variables}

We defined the primary outcome of interest in this systematic review as EGFR mutation. The prevalence of $E G F R$ mutation was defined as the proportion of patients with EGFR mutation among patients who received the mutation testing. Study location was determined using the place where the patients were recruited in the study. If the authors did not describe the patient recruitment, the affiliation address of the corresponding author was used to identify the study location. Population ethnicity was divided into Caucasian, Asian, African-American, and mixed ethnicities. Ethnicity classification was based on the information in the original publication or the principle ethnicity of each country, where the detailed information was not reported (e.g. Italy $=$ Caucasian, Japan $=$ Asian). Similarly, the classifications of smoking status, tumor histology, tumor stage, and previous use of chemotherapy were defined according to the information in original publications.

\section{Data analysis}

We conducted meta-analysis to pool the prevalence of EGFR mutation in different NSCLC patient groups. Subgroup analyses were performed according to the following factors: EGFR exons (exon 19, 21 or both, and the others), study locations (at least 50 studies in each location), ethnicity, gender, smoking status (non-smoker or past or current smoker), tumor histology (adenocarcinoma or non-adenocarcinoma), tumor stage, and previous use of chemotherapy. The within-study OR was combined to estimate the association of EGFR mutation with gender, smoking status, and tumor histology. Post-hoc subgroup analysis was conducted according to the detection methods of EGFR mutation, types of samples used in the detection, and the publication year of the study. Given the diverse nature of studies and the likely heterogeneity, we applied random-effects models to carry out meta-analysis by the Der-Simonian Laird method [51]. The statistical heterogeneity among the studies was assessed by the Cochran's Q-test and the $\mathrm{I}^{2}$ statistic. A P value $\leq 0.10$ for the Cochran's Q-test or an $\mathrm{I}^{2} \geq 50 \%$ was suggestive of significant among-study heterogeneity. We used Stata 12.0 (StataCorp, College Station, TX) to conduct all the 
analyses with a two-tailed significance level of 0.05 except in the assessment of heterogeneity $(\alpha=0.10)$.

\section{ACKNOWLEDGMENTS}

Jin-Ling Tang and Chen Mao designed the study. Chen Mao supervised the data extraction. Yue-Lun Zhang and Xiao-Ran Han analyzed data and drafted the main manuscript. All authors contributed to the writing process of the manuscript. The findings were interpreted by Yue-Lun Zhang, Chen Mao, and Diane Threapleton. Diane Threapleton and Zu-Yao Yang revised drafts of the manuscript. Kai-Feng Wang, Jin-Qiu Yuan, and XiaoHong Fu contributed to the search of published literatures and data extraction.

\section{CONFLICTS OF INTEREST} interest.

All authors declare that there are no conflicts of

\section{GRANT SUPPORT}

The work was partly supported by the Health and Medical Research Fund from Food and Health Bureau of Hong Kong (Project No.: 12130721). The funder had no role in study design, literature search, data collection and analysis, preparation of the manuscript or decision to publish. YLZ, JQY, and XRH had access to the raw data. The corresponding authors had full access to all the data and had final responsibility for the decision to submit for publication.

\section{REFERENCES}

1. International Agency for Research on Cancer, World Health Organization. GLOBOCAN: Estimated Cancer Incidence, Mortality, and Prevalence Worldwide in 2012: IARC; 2014.

2. National Comprehensive Cancer Network. Non-small cell lung cancer. 2015; www.nccn.org/professionals/physician gls/PDF/nscl.pdf. Accessed Apr 13, 2015.

3. Non-Small Cell Lung Cancer Collaborative Group. Chemotherapy and supportive care versus supportive care alone for advanced non-small cell lung cancer. The Cochrane database of systematic reviews. 2010; https://www.nccn.org/ professionals/physician_gls/pdf/nscl.pdf CD007309.

4. Cataldo VD, Gibbons DL, Pérez-Soler R, Quintás-Cardama A. Treatment of non-small-cell lung cancer with erlotinib or gefitinib. New England Journal of Medicine. 2011; 364:947-955.

5. Mok TS, Wu Y-L, Thongprasert S, Yang C-H, Chu D-T, Saijo N, Sunpaweravong P, Han B, Margono B, Ichinose Y. Gefitinib or carboplatin-paclitaxel in pulmonary adenocarcinoma. New England Journal of Medicine. 2009; 361:947-957.

6. Maemondo M, Inoue A, Kobayashi K, Sugawara S, Oizumi S, Isobe H, Gemma A, Harada M, Yoshizawa H, Kinoshita I. Gefitinib or chemotherapy for non-small-cell lung cancer with mutated EGFR. New England Journal of Medicine. 2010; 362:2380-2388.

7. Mitsudomi T, Morita S, Yatabe Y, Negoro S, Okamoto I, Tsurutani J, Seto T, Satouchi M, Tada H, Hirashima T. Gefitinib versus cisplatin plus docetaxel in patients with non-small-cell lung cancer harbouring mutations of the epidermal growth factor receptor (WJTOG3405): an open label, randomised phase 3 trial. The lancet oncology. 2010; 11:121-128.

8. Han J-Y, Park K, Kim S-W, Lee DH, Kim HY, Kim HT, Ahn MJ, Yun T, Ahn JS, Suh C. First-SIGNAL: first-line single-agent iressa versus gemcitabine and cisplatin trial in never-smokers with adenocarcinoma of the lung. Journal of Clinical Oncology. 2012; 30:1122-1128.

9. Sequist LV, Yang JC-H, Yamamoto N, O'Byrne K, Hirsh V, Mok T, Geater SL, Orlov S, Tsai C-M, Boyer M. Phase III study of afatinib or cisplatin plus pemetrexed in patients with metastatic lung adenocarcinoma with EGFR mutations. Journal of Clinical Oncology. 2013; 31:3327-3334.

10. Rosell R, Carcereny E, Gervais R, Vergnenegre A, Massuti B, Felip E, Palmero R, Garcia-Gomez R, Pallares C, Sanchez JM. Erlotinib versus standard chemotherapy as first-line treatment for European patients with advanced EGFR mutation-positive non-small-cell lung cancer (EURTAC): a multicentre, open-label, randomised phase 3 trial. The lancet oncology. 2012; 13:239-246.

11. Zhou C, Wu Y-L, Chen G, Feng J, Liu X-Q, Wang C, Zhang S, Wang J, Zhou S, Ren S. Erlotinib versus chemotherapy as first-line treatment for patients with advanced EGFR mutation-positive non-small-cell lung cancer (OPTIMAL, CTONG-0802): a multicentre, open-label, randomised, phase 3 study. The lancet oncology. 2011; 12:735-742.

12. Zhou C, Wu Y, Chen G, Feng J, Liu X, Wang C, Zhang S, Wang J, Zhou S, Ren S. (2011). Updated efficacy and quality-of-life (QoL) analyses in OPTIMAL, a phase III, randomized, open-label study of first-line erlotinib versus gemcitabine/carboplatin in patients with EGFR-activating mutation-positive (EGFR Act Mut + ) advanced non-small cell lung cancer (NSCLC). Paper presented at: ASCO Annual Meeting Proceedings2011. ASCO Annual Meeting Proceedings, pp. 7520.

13. Rosell R, Gervais R, Vergnenegre A, Massuti B, Felip E, Cardenal F, Garcia Gomez R, Pallares C, Sanchez J, Porta R. Erlotinib versus chemotherapy (CT) in advanced nonsmall cell lung cancer (NSCLC) patients (p) with epidermal growth factor receptor (EGFR) mutations: Interim results of the European Erlotinib Versus Chemotherapy (EURTAC) 
phase III randomized trial. Journal of clinical oncology. 2011;29:abs. 7503.

14. Cohen MH, Johnson JR, Chen Y-F, Sridhara R, Pazdur R.

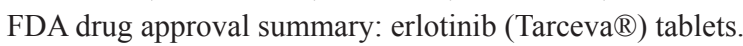
The oncologist. 2005; 10:461-466.

15. Cohen MH, Williams GA, Sridhara R, Chen G, Pazdur R. FDA drug approval summary: gefitinib (ZD1839)(Iressa ${ }^{\circledR}$ ) tablets. The oncologist. 2003; 8:303-306.

16. Gefitinib approved for use in South Korea. Inpharma Wkly. 2003;1398:22.

17. Roche. Tarceva approved for lung cancer in Japan. 2007; http://www.pharmatimes.com/news/japan_approves roches_tarceva_for_non-small_cell_lung_cancer_991183. Accessed Nov 23, 2015.

18. China Food and Drug Administration. CFDA drug approval for gefitinib. 2014; http://www.astrazeneca.com.cn/cs/Satellite?blo bcol=urldata\&blobheader=application $\% 2$ Fpdf\&blobheaderna me1=Content-Disposition\&blobheadername $2=$ MDT-Type \&bl obheadervalue $1=$ inline $\% 3 B+$ filename $\% 3 D 261312979027801$. pdf\&blobheadervalue $2=$ abinary $\% 3 \mathrm{~B}+$ charset $\% 3 \mathrm{DUTF}-8 \&$ blo bkey $=$ id\&blobtable $=$ MungoBlobs\&blobwhere $=12857108116$ 55\&ssbinary=true. Accessed Nov 24, 2015.

19. U.S. Food and Drug Administration. FDA approves targeted therapy for first-line treatment of patients with a type of metastatic lung cancer. 2015; http://www.fda.gov/ NewsEvents/Newsroom/PressAnnouncements/ucm454678. htm. Accessed Nov 24, 2015.

20. Azzoli CG, Temin S, Aliff T, Baker S, Brahmer J, Johnson DH, Laskin JL, Masters G, Milton D, Nordquist L. 2011 focused update of 2009 American Society of Clinical Oncology clinical practice guideline update on chemotherapy for stage IV non-small-cell lung cancer. Journal of Clinical Oncology. 2011; 29:3825-3831.

21. Pirker R, Herth FJ, Kerr KM, Filipits M, Taron M, Gandara D, Hirsch FR, Grunenwald D, Popper H, Smit E. Consensus for EGFR mutation testing in non-small cell lung cancer: results from a European workshop. Journal of Thoracic Oncology. 2010; 5:1706-1713.

22. Haneda H, Sasaki H, Lindeman N, Kawano O, Endo K, Suzuki E, Shimizu S, Yukiue H, Kobayashi Y, Yano M. A correlation between EGFR gene mutation status and bronchioloalveolar carcinoma features in Japanese patients with adenocarcinoma. Japanese journal of clinical oncology. 2006; 36:69-75

23. Chou T-Y, Chiu C-H, Li L-H, Hsiao C-Y, Tzen C-Y, Chang K-T, Chen Y-M, Perng R-P, Tsai S-F, Tsai C-M. Mutation in the tyrosine kinase domain of epidermal growth factor receptor is a predictive and prognostic factor for gefitinib treatment in patients with nonsmall cell lung cancer. Clinical cancer research. 2005; 11:3750-3757.

24. Tsao M-S, Sakurada A, Cutz J-C, Zhu C-Q, Kamel-Reid S, Squire J, Lorimer I, Zhang T, Liu N, Daneshmand M. Erlotinib in lung cancer-molecular and clinical predictors of outcome. New England Journal of Medicine. 2005; 353:133-144.

25. Cappuzzo F, Hirsch FR, Rossi E, Bartolini S, Ceresoli GL, Bemis L, Haney J, Witta S, Danenberg K, Domenichini I. Epidermal growth factor receptor gene and protein and gefitinib sensitivity in non-small-cell lung cancer. Journal of the National Cancer Institute. 2005; 97:643-655.

26. Mitsudomi T, Kosaka T, Endoh H, Horio Y, Hida T, Mori S, Hatooka S, Shinoda M, Takahashi T, Yatabe Y. Mutations of the epidermal growth factor receptor gene predict prolonged survival after gefitinib treatment in patients with non-smallcell lung cancer with postoperative recurrence. Journal of Clinical Oncology. 2005; 23:2513-2520.

27. Marchetti A, Martella C, Felicioni L, Barassi F, Salvatore S, Chella A, Camplese PP, Iarussi T, Mucilli F, Mezzetti A. EGFR mutations in non-small-cell lung cancer: analysis of a large series of cases and development of a rapid and sensitive method for diagnostic screening with potential implications on pharmacologic treatment. Journal of Clinical Oncology. 2005; 23:857-865.

28. Han S-W, Kim T-Y, Hwang PG, Jeong S, Kim J, Choi IS, Oh D-Y, Kim JH, Kim D-W, Chung DH. Predictive and prognostic impact of epidermal growth factor receptor mutation in non-small-cell lung cancer patients treated with gefitinib. Journal of clinical oncology. 2005; 23:2493-2501.

29. Shigematsu H, Lin L, Takahashi T, Nomura M, Suzuki M, Wistuba II, Fong KM, Lee H, Toyooka S, Shimizu N. Clinical and biological features associated with epidermal growth factor receptor gene mutations in lung cancers. Journal of the National Cancer Institute. 2005; 97:339-346.

30. Jänne PA, Engelman JA, Johnson BE. Epidermal growth factor receptor mutations in non-small-cell lung cancer: Implications for treatment and tumor biology. Journal of Clinical Oncology. 2005; 23:3227-3234.

31. Shi Y, Au JS-K, Thongprasert S, Srinivasan S, Tsai C-M, Khoa MT, Heeroma K, Itoh Y, Cornelio G, Yang P-C. A prospective, molecular epidemiology study of EGFR mutations in Asian patients with advanced non-small-cell lung cancer of adenocarcinoma histology (PIONEER). Journal of Thoracic Oncology. 2014; 9:154.

32. Kosaka T, Yatabe Y, Endoh H, Kuwano H, Takahashi T, Mitsudomi T. Mutations of the epidermal growth factor receptor gene in lung cancer biological and clinical implications. Cancer research. 2004; 64:8919-8923.

33. Sharma SV, Bell DW, Settleman J, Haber DA. Epidermal growth factor receptor mutations in lung cancer. Nature Reviews Cancer. 2007; 7:169-181.

34. Dearden S, Stevens J, Wu Y-L, Blowers D. Mutation incidence and coincidence in non small-cell lung cancer: meta-analyses by ethnicity and histology (mutMap). Annals of Oncology. 2013:mdt205.

35. Szumera-Ciećkiewicz A, Olszewski WT, Tysarowski A, Kowalski DM, Głogowski M, Krzakowski M, Siedlecki JA, Wągrodzki M, Prochorec-Sobieszek M. EGFR mutation 
testing on cytological and histological samples in nonsmall cell lung cancer: a Polish, single institution study and systematic review of European incidence. International journal of clinical and experimental pathology. 2013; 6:2800.

36. Midha A, Dearden S, McCormack R. EGFR mutation incidence in non-small-cell lung cancer of adenocarcinoma histology: a systematic review and global map by ethnicity (mutMapII). American journal of cancer research. 2015; 5:2892.

37. Wang S, Wang Z. EGFR mutations in patients with nonsmall cell lung cancer from mainland China and their relationships with clinicopathological features: a metaanalysis. International journal of clinical and experimental medicine. 2014; 7:1967.

38. Ren JH, He WS, Yan GL, Jin M, Yang KY, Wu G. EGFR mutations in non-small-cell lung cancer among smokers and non-smokers: A meta-analysis. Environmental and molecular mutagenesis. 2012; 53:78-82.

39. Ueno T, Toyooka S, Suda K, Soh J, Yatabe Y, Miyoshi S, Matsuo K, Mitsudomi T. Impact of age on epidermal growth factor receptor mutation in lung cancer. Lung Cancer. 2012; 78:207-211.

40. D'Angelo SP, Pietanza MC, Johnson ML, Riely GJ, Miller VA, Sima CS, Zakowski MF, Rusch VW, Ladanyi M, Kris MG. Incidence of EGFR exon 19 deletions and L858R in tumor specimens from men and cigarette smokers with lung adenocarcinomas. Journal of Clinical Oncology. 2011; 29:2066-2070.

41. Girard N, Sima C, Jackman DM, Sequist LV, Chen H, Yang J-H, Ji H, Waltman B, Rosell R, Taron M. Nomogram to predict the presence of EGFR activating mutation in lung adenocarcinoma. European Respiratory Journal. 2012; 39:366-372.

42. Wang M, Zhang X, Zhang X, Zhang L, Zhong W, Xu L, Li L. Efficacy and safety of erlotinib as monotherapy for advanced non-small cell lung cancer. Acta Academiae Medicinae Sinicae. 2010; 32:151-156.

43. Shi Y, Li J, Zhang S, Wang M, Yang S, Li N, Wu G, Liu W, Liao G, Cai K. Molecular Epidemiology of EGFR Mutations in Asian Patients with Advanced Non-SmallCell Lung Cancer of Adenocarcinoma Histology-Mainland China Subset Analysis of the PIONEER study. PloS one. 2015; 10:e143515.

44. Leighl NB, Rekhtman N, Biermann WA, Huang J, MinoKenudson M, Ramalingam SS, West H, Whitlock S,
Somerfield MR. Molecular testing for selection of patients with lung cancer for epidermal growth factor receptor and anaplastic lymphoma kinase tyrosine kinase inhibitors: American society of clinical oncology endorsement of the college of american pathologists/international society for the study of lung cancer/association of molecular pathologists guideline. Journal of Clinical Oncology. 2014:JCO. 2014.2057. 3055.

45. de Lima Lopes G, Segel JE, Tan DS, Do YK, Mok T, Finkelstein EA. Cost-effectiveness of epidermal growth factor receptor mutation testing and first-line treatment with gefitinib for patients with advanced adenocarcinoma of the lung. Cancer. 2012; 118:1032-1039.

46. Salto-Tellez M, Tsao M-S, Shih J-Y, Thongprasert S, Lu S, Chang G-C, Au JS-K, Chou T-Y, Lee J-S, Shi Y-K. Clinical and testing protocols for the analysis of epidermal growth factor receptor mutations in East Asian patients with nonsmall cell lung cancer: a combined clinical-molecular pathological approach. Journal of Thoracic Oncology. 2011; 6:1663-1669.

47. Qian X, Liu J, Sun Y, Wang M, Lei H, Luo G, Liu X, Xiong C, Liu D, Liu J. Circulating cell-free DNA has a high degree of specificity to detect exon 19 deletions and the singlepoint substitution mutation L858R in non-small cell lung cancer. Oncotarget. 2016; 7:29154-29165. doi: 10.18632/ oncotarget.8684.

48. Xue C, Hu Z, Jiang W, Zhao Y, Xu F, Huang Y, Zhao H, $\mathrm{Wu}$ J, Zhang Y, Zhao L. National survey of the medical treatment status for non-small cell lung cancer (NSCLC) in China. Lung Cancer. 2012; 77:371-375.

49. Choi Y-L, Sun J-M, Cho J, Rampal S, Han J, Parasuraman B, Guallar E, Lee G, Lee J, Shim YM. EGFR mutation testing in patients with advanced non-small cell lung cancer: a comprehensive evaluation of real-world practice in an East Asian tertiary hospital. PloS one. 2013; 8:e56011.

50. Yoshizawa A, Sumiyoshi S, Sonobe M, Kobayashi M, Fujimoto M, Kawakami F, Tsuruyama T, Travis WD, Date H, Haga H. Validation of the IASLC/ATS/ERS lung adenocarcinoma classification for prognosis and association with EGFR and KRAS gene mutations: analysis of 440 Japanese patients. Journal of Thoracic Oncology. 2013; 8:52-61.

51. DerSimonian R, Laird N. Meta-analysis in clinical trials. Controlled clinical trials. 1986; 7:177-188. 